\title{
Tipps und Tricks: Entfernung von „Elastic-Nails“
}

\section{$\square$ Dankward Höntzsch}

Wenn „Elastic-Nails“ ausreichend über der Knochenoberfläche herausschauen, können diese mit Zangen gefasst werden. Häufig liegen die Enden in oder sogar unter dem Knochenniveau oder schauen nur so knapp darüber hinaus, dass es nicht einfach ist, das Ende mit einer Zange zu fassen. Außerdem verbrauchen die Zangen relativ viel Platz, sodass die Inzision ausreichend groß sein muss.

Eine elegante Entfernungsmethode ist:

Das Ende des „Elastic-Nails“ wird nur so weit wie notwendig dargestellt. Dann wird das Ende mit dem Instrumentarium zum Entfernen abgebrochener

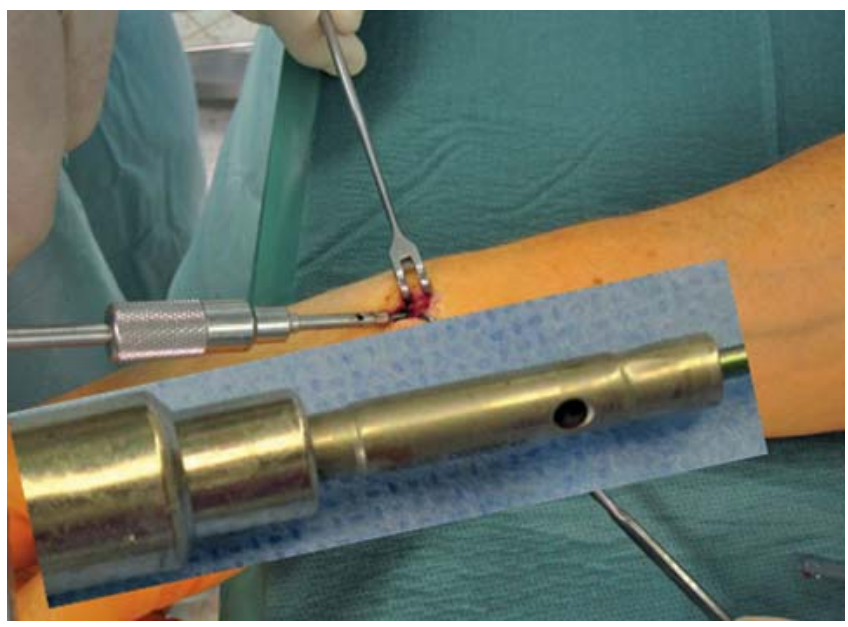
Schraubenschäfte entfernt:

Zunächst wird der Elastic-Nail linksdrehend überbohrt. Dann wird das Ende mit dem linksdrehenden Extraktionsbolzen gegriffen und der Nagel kann herausgezogen oder mit leichten Hammerschlägen gelockert und dann herausgezogen werden.

Der „Flurschaden“ beim Entfernen von Elastic-Nails ist mit dieser Methode deutlich geringer als mit Zangen. 